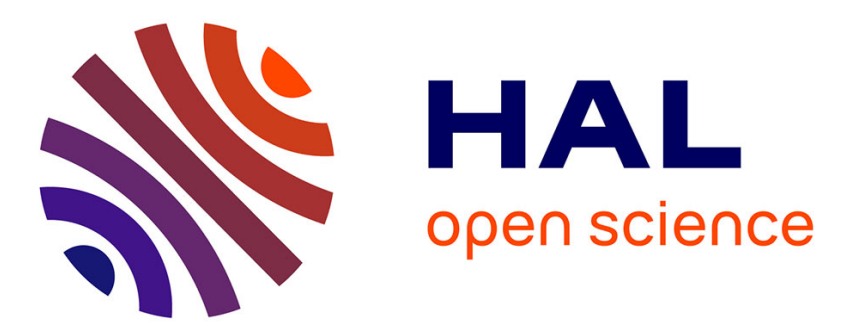

\title{
Thermodynamic analysis of the breathing of amino-functionalized MIL-53(Al) upon CO2 adsorption
}

Anne Boutin, Sarah Couck, François-Xavier Coudert, Pablo Serra-Crespo, Jorge Gascon, Freek Kapteijn, Alain Fuchs, Joeri F.M. Denayer

\section{To cite this version:}

Anne Boutin, Sarah Couck, François-Xavier Coudert, Pablo Serra-Crespo, Jorge Gascon, et al.. Thermodynamic analysis of the breathing of amino-functionalized MIL-53(Al) upon CO2 adsorption. Microporous and Mesoporous Materials, 2011, 140 (1-3), pp.108-113. 10.1016/j.micromeso.2010.07.009 . hal-02142935

\section{HAL Id: hal-02142935 \\ https://hal.science/hal-02142935}

Submitted on 29 May 2019

HAL is a multi-disciplinary open access archive for the deposit and dissemination of scientific research documents, whether they are published or not. The documents may come from teaching and research institutions in France or abroad, or from public or private research centers.
L'archive ouverte pluridisciplinaire HAL, est destinée au dépôt et à la diffusion de documents scientifiques de niveau recherche, publiés ou non, émanant des établissements d'enseignement et de recherche français ou étrangers, des laboratoires publics ou privés. 


\title{
Thermodynamic Analysis of the Breathing of Amino-functionalized MIL-53(Al) upon $\mathrm{CO}_{2}$ Adsorption
}

\author{
Anne Boutin ${ }^{\mathrm{a}, *}$, Sarah Couck ${ }^{\mathrm{b}}$, François-Xavier Coudert ${ }^{\mathrm{c}}$, Pablo Serra-Crespo ${ }^{\mathrm{d}}$, \\ Jorge Gascon ${ }^{\text {d }}$, Freek Kapteijn ${ }^{\mathrm{d}}$, Alain H. Fuchs ${ }^{\mathrm{c}}$, Joeri F. M. Denayer ${ }^{\mathrm{b}, *}$
}

a. Ecole Normale Supérieure, Département de chimie, Laboratoire PASTEUR, UPMC-CNRS, Paris, France

b. Department of Chemical Engineering, Vrije Universiteit Brussels, Brussels, Belgium

c. Chimie ParisTech \& CNRS, Paris, France

d. Catalysis Engineering, Delft University of Technology, Delft, The Netherlands

* Corresponding authors;

Email addresses: anne.boutin@ens.fr, Joeri.Denayer@vub.ac.be

\begin{abstract}
Carbon dioxide gas adsorption in amino-functionalized MIL-53(Al) at various temperatures has been analysed in combination with temperature programmed XRD. Similarly to the regular MIL-53(Al) material, the so-called breathing phenomenon was shown to take place in the amino-MIL-53 upon adsorption of different molecules, i.e. the transition between a large pore (lp) and a narrow-pore (np) structure. Using the osmotic thermodynamic model analysis, the temperature-loading phase diagram was derived. The overall diagram is similar to that for the regular MIL-53(Al), but a spectacular difference is the much larger stability domain of the np structure, which can be accounted for by the increased affinity for $\mathrm{CO}_{2}$ due to the presence of the amino groups in the pore space.
\end{abstract}

\section{Keywords:}

Metal-Organic-Framework; thermodynamics; adsorption; theory 


\section{Introduction}

The overwhelming share of fossil fuels among the primary sources of energy throughout the world, and their combustion is one of the major sources of carbon dioxide. Since commercial $\mathrm{CO}_{2}$ capture technology that exists today is very expensive and energy intensive, the development of improved adsorbents for $\mathrm{CO}_{2}$ separation from flue gas is considered a key step in carbon dioxide sequestration. In addition to more conventional porous materials such as mesoporous silicates, carbons and zeolites, many types of Metal-Organic Frameworks (MOF) have been tested during the last few years for their ability to adsorb $\mathrm{CO}_{2}[1-8]$ and to separate $\mathrm{CO}_{2}$ from gas mixtures [9-20]. While some of these materials have extremely large $\mathrm{CO}_{2}$ uptake capacities, their selectivity for separating $\mathrm{CO}_{2}$ from mixtures with other gases does not often exceed that of zeolitic adsorbents such as 13X or Ca-CHA [21]. An overview of the different adsorbents relevant for $\mathrm{CO}_{2}$ separation processes together with data on selectivity and capacity is given in the recent review of Tagliabue et al on natural gas treating by adsorption [22].

Adding functional groups with a high affinity towards $\mathrm{CO}_{2}$ to the MOF framework is an obvious way to enhance the $\mathrm{CO}_{2}$ selectivity. Amine groups are preferred functionalities, as industrial absorption processes for $\mathrm{CO}_{2}$ capture rely on the use of weakly basic aqueous amine solutions, although other hydroxyl groups have also been proposed on the basis of theoretical investigations [23]. Amines have been grafted successfully on the surface of mesoporous silicas and zeolites [24-32], and also several MOFs containing amine groups have been prepared [33-43].

In previous work, we have reported on the synthesis of amino-MIL-53(Al), using 2aminoterephthalic acid as linker [44]. By performing pulse gas chromatographic experiments and breakthrough separation experiments with undiluted mixtures of $\mathrm{CO}_{2}$ and $\mathrm{CH}_{4}$, we have demonstrated that the selectivity of this material by far exceeds that of the parent MIL-53(Al) framework $[45,46]$. While methane is nearly not adsorbed by amino-MIL-53(Al), $\mathrm{CO}_{2}$ is strongly captured, leading to unrivalled selectivities in the separation of both gases. MIL-53 is built up from $\mathrm{MO}_{4}(\mathrm{OH})_{2}$ octahedra (where $\mathrm{M}$ can be $\mathrm{Fe}^{3+}, \mathrm{Cr}^{3+}, \mathrm{Ga}^{3+}$ or $\mathrm{Al}^{3+}$ ) and 1,4benzenedicarboxylate (terephtalate) linkers. A crystalline material with 1-D diamond shaped pores, with a free diameter of $8.6 \AA$, is formed [3]. Amino-MIL-53(Al) is a material based on the topology of MIL-53. During synthesis of amino-MIL-53, 2-amino terephtalic acid is used 
as linker molecule instead of terephtalic acid. The obtained material also contains 1-D diamond shaped channels, having a free diameter close to $7.5 \AA$, with free standing amino groups in the pores [46].

Both materials (regular- and amino-MIL53) have two distinct crystallographic structures, one which has narrow pores, with a smaller cell and pore volume, and one with larger, more open pores; these structures are named narrow-pore (np) and large-pore (lp). Both materials exhibit two successive guest-induced structure transitions ("breathing") upon $\mathrm{CO}_{2}$ adsorption at room temperature, from lp to $\mathbf{n p}$, and then from $\mathbf{n p}$ back to $\mathbf{l p}$ at higher pressure. This phenomenon and its temperature dependency have by now been widely studied only for regular MIL-53. However, the behaviour of amino-MIL53 may differ from regular-MIL-53, as evidenced by the fact that the breathing pressures for $\mathrm{CO}_{2}$ at room temperature are not the same. One way to investigate these differences is to consider the energetics of the host-guest interactions (i.e. their $0 \mathrm{~K}$ interaction energies) as in the recent work of Mellot-Draznieks and co-workers [47] using quantum chemistry calculations. However, as temperature widely influences (and even reverses) the behaviour of MIL-53 upon gas adsorption, a more comprehensive approach is needed. In this article, we present a new thermodynamic insight into this phenomenon, by analysis of experimental data over a wide temperature range using theoretical models (following ref. [48]).

\section{Experiments}

\subsection{Synthesis and characterisation}

Amino-MIL-53(Al) was synthesized using the method described in [44]. In brief $2.10 \mathrm{mmol}$ aluminium nitrate nonahydrate dissolved in $15 \mathrm{~mL}$ DMF and $3.12 \mathrm{mmol}$ 2-aminoterephthalic acid dissolved in $15 \mathrm{ml}$ DMF were mixed in a Teflon insert and placed in an autoclave. The autoclave was kept at $403 \mathrm{~K}$ for 3 days. The yellow gel product was filtered off and washed with acetone. After acetone removal, the product was washed overnight with boiling methanol under reflux and dried at $110^{\circ} \mathrm{C}$ in vacuum for $8 \mathrm{~h}$.

Temperature programmed in situ powder XRD measurements (TP-XRD) were performed to study the framework stability at high temperatures by a Bruker-AXS D5005 diffractometer in 
Bragg-Brentano focusing geometry, equipped with a graphite monochromator in the diffracted beam. The sample powder was deposited as a thin layer on a Pt heater strip in an MRI high temperature camera. During the measurement this camera was flushed continuously with high purity nitrogen gas. The $\theta-2 \theta$ scan was made in the range $5-60^{\circ}(2 \theta)$, using a step size of $0.02^{\circ}(2 \theta)$ and a counting time per step of $2 \mathrm{~s}$. The radiation was $\mathrm{Cu} \mathrm{K \alpha 1}$. Data evaluation was done with the Bruker program EVA. In situ XRD patterns in $\mathrm{N}_{2}$ flow were recorded isothermally at intervals of $100{ }^{\circ} \mathrm{C}$ in the temperature range of $30-500{ }^{\circ} \mathrm{C}$, both at increasing and decreasing temperature.

\subsection{Adsorption isotherms measurements}

Adsorption isotherms of $\mathrm{CO}_{2}$ (purity of $99.995 \%$ ) were determined using the volumetric method using about $0.5 \mathrm{~g}$ of amino-MIL-53(Al) sample. Before every measurement, the adsorbent was regenerated by raising the temperature to $423 \mathrm{~K}$ at a rate of $1 \mathrm{~K} / \mathrm{min}$ under vacuum $\left(10^{-7} \mathrm{mbar}\right)$. Isotherms were measured at $253,283,293,303,313,363$ and $393 \mathrm{~K}$. The temperature of the sample was controlled using a thermostat with recirculation.

\subsection{Adsorption isotherms results}

The adsorption and desorption isotherms, measured at room temperature, clearly exhibit steps and hysteresis loop (see Figure 1) which can be linked to adsorption-induced structural transitions (breathing). The amount of $\mathrm{CO}_{2}$ molecules adsorbed per unit cell are lower by a factor of $\sim 1.5$ compared to the adsorbed quantities measured in regular MIL-53(Al) [49]. The presence of amino groups thus leads to a decrease of the pore volume due to the presence of a narrower pore structure. Indeed, we recently reported the effective pore opening of the amino functionalized compound to be smaller ( $6 \AA$ ) than that of the non-functionalized material (8 A) [50]. We attribute this smaller effective pore size to the presence of free-standing aminogroups in the pores and to a partial contraction of the framework due to the interaction between amino-groups and hydroxyl groups.

The step between 5-15 bar in the isotherm can clearly be attributed to the opening of the material (np-lp transition).

The adsorption isotherms measured at various temperatures ranging from 253 to $313 \mathrm{~K}$ clearly display a phase transition similar to the one described at room temperature (see Figure 2). 
Adsorption isotherms measured at higher temperatures (363 and $393 \mathrm{~K}$ ) have different shapes and will be discussed later using the thermodynamic analysis.

\section{Temperature programmed XRD}

Temperature programmed XRD was performed on an activated amino-MIL-53(Al) sample under $\mathrm{N}_{2}$ atmosphere. Results are plotted in Figure 3.

At room temperature, for the fresh sample with solvent molecules present in the structure, characteristic peaks for both the $\mathbf{l p}$ structure at $2 \theta=9.5^{\circ}$ and the $\mathbf{n p}$ structure at $2 \theta=13^{\circ}$ are observed, indicating that a mixture of both forms is present. However, as the sample is heated up from $373 \mathrm{~K}$ no sudden breathing is observed. Although the cell expands with temperature no clear opening of the structure takes place.

It has been reported for the chromium and aluminium forms of MIL-53 (unfunctionalized) that dehydration yields to a sudden expansion of the unit cell due to the elimination of hydrogen bonding inside the structure (both guest-guest and symmetrical host-guest) [3,51]. More recently, with the results of other MIL-53 structures like the Fe based one, that does not show any breathing upon dehydration or MIL-53(Ga), that shows an intermediate behavior, it was hypothesized that even if hydrogen bonding in the hydrated forms may play a key role in the breathing behavior, the nature of the metal in the nodes, more specifically the ionic radius and the electronic properties, is also of large relevance for the whole breathing phenomenon $[52,53]$.

In contrast to these previous reports, the amino functionalized material represents a different case. Since hydrogen bonding already occurs due to the weak interaction $\mathrm{H}_{2} \mathrm{~N} \leftrightarrow \mathrm{HO}$ in the structure itself, the opening of the structure via dehydration is hampered. In contrast to other MIL-53 materials [54], in view of the reversibility shown in Figure 3, no large hysteresis occurs. This stronger interaction within the framework would account for the higher adsorbate pressures needed to completely open the framework, as shown below in the thermodynamic analysis. 


\section{Thermodynamics analysis}

\subsection{Analytical thermodynamic model}

In order to rationalize the behaviour of amino-MIL-53 observed experimentally, we have applied a thermodynamic model, called the osmotic thermodynamic model [56]. This model is based on the so-called "osmotic ensemble", which is the appropriate statistical ensemble to describe fluid adsorption in a flexible porous material. For materials exhibiting clear structural transitions between different metastable framework structures (as opposed to the phenomenon of progressive, continuous swelling for instance), we demonstrated in earlier works that the use of an osmotic sub-ensemble adequately describes the equilibrium between host structures upon fluid adsorption [56,57]. This model was validated on a certain number of guest-driven structural transitions in soft porous crystals, including gate opening and breathing effects. It was successfully applied to understand the presence or absence of breathing in MIL-53(Al) upon adsorption of small gas molecules such as $\mathrm{CO}_{2}, \mathrm{CH}_{4}$, and linear alkanes at room temperature. [56-58]

It is to be noted here that one of the key requirements of the model is the ability to provide "rigid host" isotherms for each phase (i.e. metastable structure) of the host material. In previous studies, we showed that Langmuir fits of parts of the stepped isotherms belonging to each phase are usually powerful enough to describe the adsorption process. In particular, in our previous studies of MIL-53(Al), we used Langmuir fits of the experimental isotherms as approximations to the rigid host isotherms in both the $\mathbf{l p}$ and $\mathbf{n p}$ structures. Other authors have derived the generic equations of the model in order to use a different isotherm equation, namely the Langmuir-Freundlich model [59].

Based on this thermodynamic framework of the coupling of the material's flexibility upon adsorption, various applications have been proposed. For example, it was demonstrated that a more mechanical view of the structural transition could be coupled together with the thermodynamic equations of adsorption, in order to put forward a hypothesis for experimental observations of the coexistence of multiple phases for some pressure ranges upon adsorption [60]. Also, by coupling the osmotic ensemble with methods of coadsorption prediction, like the Ideal Adsorbed Solution Theory, one can rationalize and predict the evolution of structural 
transitions and selectivity upon adsorption of fluid mixtures [58], a very important prospect since one of the main potential applications of these materials is adsorptive separation.

Finally, in a recent study of xenon adsorption on MIL-53(Al) [48], stepped isotherms obtained at different temperatures were used to determine the temperature-dependent properties of the lp and $\mathbf{n p}$ structures, including their xenon adsorption properties (maximal loading and Henry constants), but also the evolution of the free energy difference $\Delta F_{\mathbf{l p}-\mathbf{p p}}(T)$ with temperature, i.e. the enthalpy and entropy difference, $\Delta H_{\text {Ip-np }}$ and $\Delta S_{\text {Ip-np. In turn, this }}$ allowed the prediction of a complete, continuous diagram of the evolution of breathing, in the form of a bidimensional Temperature- Gas pressure phase diagram of the lp and $\mathbf{n p}$ structures [48].

\subsection{Adsorption isotherms fitting}

We apply the thermodynamic model based on these experimental data using simple Langmuir equation to fit the low and high-pressure regions (i.e. before and after the step in the isotherms). The adsorption isotherms are satisfactorily fitted in the high-pressure region (i.e. Ip form) (see Figure S1). This is not the case at low-pressure. The isotherm shapes are hardly compatible with a pure Langmuir equation (see Figure 4).

There are several ways to tackle this issue. One way is to use a non-Langmuirian adsorption isotherm analytical model. We indeed observed that the low-pressure experimental data can be well fitted using Langmuir-Freundlich equation for instance. Another way is to consider that the low pressure regime is due to the presence of phase mixtures. While both options lead to similar fit agreement, the second option leads to coherent model parameters with experimental data and previous analysis on regular MIL-53(Al). Indeed, phase mixture was observed for the material at room temperature (see section 3). It is worth mentioning that this working hypothesis allows good description of the data, but that no direct experimental results are yet available.

We adapted our procedure to deal with phase mixture in an effective way: fitting by mixtures of two Langmuir equations, i.e. two Langmuir isotherms in a certain ratio accounting for a fraction of the lp form at low pressure. We used the Langmuir parameters determined at high pressure and thus adjust only three parameters (the two Langmuir parameters of the np form 
and the fraction of the lp form) in the low pressure resulting in good fits (see Figures 4 and S2). This leads to an Ip fraction of $\sim 20 \%$ almost constant in the $n p$ domain. (see Figure S3). Phase mixture was already observed in regular MIL-53 and such an $\mathbf{n p} / \mathbf{l p}$ fraction was observed [33,61].

The resulting fit parameters $N_{\max }$ (see Figure S4) have linear evolution with $T$ and coherent with adsorption loadings found in MIL-53. The values of the Henry coefficient $K$ are also reasonable and coherent with the chromatography experiments (see Figure S5). The chromatography data were not used for prediction of $K$ values. Considering the value of $K$ extracted from the fitting of the isotherms, the chromatography $K$ value would correspond to a fraction of the np phase of less than $5 \%(x>0.95)$. The chromatography data thus correspond to the Ip phase (a small fraction of $\mathbf{n p}$ phase leads to a large increase of the $K$ value since the $K_{n p}$ is much larger than $K_{l p}$ ).

As explained in full details in $[48,56]$, the next step consists of feeding the thermodynamic osmotic model with the isotherm fitting parameters, in order to predict the np-lp transition pressure at each temperature.

\subsection{Phase diagram prediction}

To compute the temperature- $\mathrm{CO}_{2}$ pressure $\left(T, P_{\mathrm{CO} 2}\right)$ phase diagram for $\mathrm{CO}_{2}$ in amino-MIL, we need to know how the affinity $K$ and the maximum loading $N_{\max }$ parameters change with temperature, for each phase. These are obtained through a simple fit of the existing data (Figures S4 and S5). In addition to the $K$ and $N_{\max }$ values in the lp and np phases at all temperatures, the calculation of the phase diagram requires $\Delta H_{\text {host }}$ and $\Delta S_{\text {host }}$, the enthalpy and entropy change associated with the np-lp phase transition of the bare material:

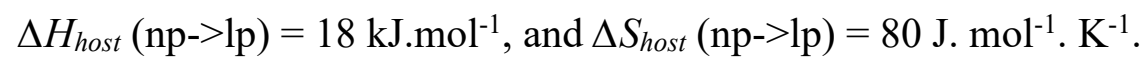

These values are somehow larger that the ones estimated for regular MIL-53(Al) material $\left(\Delta H_{\text {host }}(\mathrm{MIL}-53)=15 \mathrm{~kJ} \cdot \mathrm{mol}^{-1}\right.$ and $\left.\Delta S_{\text {host }}(\mathrm{MIL}-53)=\mathrm{J} \cdot \mathrm{mol}^{-1} \cdot \mathrm{K}^{-1}\right)[48]$. The equilibrium phase transition temperature between the $\mathbf{l p}$ and $\mathbf{n p}$ phases at zero pressure (i.e. empty material) is thus $T_{0}=226 \pm 10 \mathrm{~K}$ (compared to $T_{0}=203 \mathrm{~K}$ for regular MIL-53). The np phase is stable below $T_{0}$ while the lp one is stable above $T_{0}$. 
Using all these 10 parameters, we can compute the $\left(T, P_{\mathrm{CO} 2}\right)$ phase diagram (Figure 5). The predicted diagram is consistent with the experimental transition pressures. The diagram boundary lies between adsorption and desorption points, as it ought to be since the model correspond to the thermodynamic equilibrium.

Due to the large number of unknowns in this problem, more than one set of model parameters could reproduce the available data. We chose a set of parameters that are in fair agreement with known properties of the amino-MIL and other materials of this family $\left(\Delta H_{a d s}, \Delta H_{\text {host }}\right.$ and $\left.\Delta S_{h o s t}\right)$. A sensitivity analysis showed that varying the model parameters didn't change much the shape of the phase diagram.

The presented $(\mathrm{T}, \mathrm{P})$ diagram represents the equilibrium transition pressure between the $\mathbf{n p}$ and the lp forms. The fact that the transitions spread over a range of pressures and that the adsorption-desorption isotherms present a hysteretic loop have been previously interpreted in the regular MIL-53(Al) material using the so called "stress model" [60]. This model considers that the phase transformation in the host structure happens at a certain critical stress threshold that the material in a given phase cannot withstand. As a consequence, this model implies that the adsorption-desorption isotherms exhibit hysteresis loops, since the structural transition pressure depends on the stress threshold of the host structure before the transition, rather than on the condition of thermodynamic equilibrium between the phases. Assuming that the experimental sample is composed of a large number of crystallites of different sizes, the stress model provides an explanation of observed smooth transitions. We introduced an arbitrary uncertainty of $\pm 1 \mathrm{~kJ} \cdot \mathrm{mol}^{-1}$ introduced in the osmotic potential to visualize the spread in transition pressure in Figure 5.

\subsection{High temperature isotherms}

As mentioned above, two high temperature isotherms were also measured (at 363 and $393 \mathrm{~K}$, see Figure 6). These two isotherms display inflections that were not easy to analyse in first place, and the corresponding data were not included in the thermodynamic analysis presented before. The Langmuir isotherms corresponding to the pure Ip structure, taken from the low temperature fits, are shown in the same Figure. A comparison between these lp Langmuir and measured isotherms clearly show that some breathing (at least partial) does actually happen at 
these temperature. At $393 \mathrm{~K}$, the deviation from the Langmuir predictions could be understood in terms of $\mathbf{l p} \rightarrow \mathbf{n p} \rightarrow \mathbf{l p}$ breathing, in the 3-22 bar range. At $363 \mathrm{~K}$, the first (lp $\rightarrow$ np closing) transition seems to take place just below 5 bar, and the full reopening would occur outside the experimental pressure window ( $>30 \mathrm{bar}$ ).

As these two temperatures are close to the higher bounds of the predicted phase diagram (Figure 5), the present analysis provides a good view of the uncertainty of the thermodynamic analysis. The data at $363 \mathrm{~K}$ are in good agreement with the predicted phase diagram (Figure 5, see the "stars" in the diagram). At 393 K, it was predicted that no transition should take place. The "stars" in the diagram at $393 \mathrm{~K}$ show, however, that the extra experimental data at high temperature are consistent with the predicted phase diagram, provided that some (unavoidable) uncertainties are taken into account.

\section{Comparison with regular MIL-53(AI)}

The amino-MIL-53(Al) phase diagram can be compared with the recently determined regularMIL-53(Al) diagram [62]. In both cases the phase diagram is similar to one previously determined in the case of the $\{\mathrm{Xe}, \mathrm{MIL}-53(\mathrm{Al})\}$ system [48]. It starts from the equilibrium np-lp temperature $T_{0}(203 \mathrm{~K}$ at zero pressure for regular MIL-53 and $226 \mathrm{~K}$ for amino-MIL53). The initial slope of the transition line in this phase diagram is proportional to the logarithm of $\left(K_{\mathrm{np}} / K_{\mathrm{lp}}\right)$, the ratio of adsorption affinities in the two structures, and is thus strictly positive since the affinity of the guest adsorbate for the closed form of the framework is higher than for the open form. The condition $K_{\mathrm{np}} / K_{\mathrm{lp}}>1$ thus favours the closed np phase, and consequently the phase transition temperature increases with the gas loading (i.e. the stability domain of the np phase increases with $P_{\mathrm{CO} 2}$ ). As seen in Figure 7, the initial slope of the transition line is higher in the case of the amino-MIL system.

At higher temperature, the free energy difference between the two forms increases, and it becomes more and more difficult to maintain the np form as the most stable one. This causes the observed bending of the transition line. For obvious entropy reasons, the Ip phase will eventually become more stable at high temperature, regardless of the gas loading. This situation is also true at high pressure. As the adsorbate pressure increases, at any temperature, the Ip structure will eventually become more stable than the np one because it can accommodate a higher loading of guest molecules. Since the lp phase is the most stable one at 
high enough temperature as well as at high adsorbate pressure, one has to conclude that the stability domain of the np phase should be limited in adsorbate pressure $\left(P_{\max } \sim 5\right.$ bar in the case of regular MIL and almost 40 bar in the case of amino-MIL), as is seen in Figure 7. Even though the overall shape of the temperature-gas pressure phase diagram is similar, there is a spectacular difference in the stability domain of the np structure, which can be accounted for by the increased stability of this form due to the presence of the amino groups in the structure. The strong affinity of $\mathrm{CO}_{2}$ molecules in the $\mathbf{n p}$ form leads to a larger value of $K_{\mathrm{np}} / K_{\mathrm{lp}}$ for the amino-MIL material compared to the regular MIL53 and enlarges the stability domain of the np form.

\section{Conclusions}

A series of carbon dioxide gas adsorption experiments at various temperatures, combined with temperature programmed XRD and the osmotic thermodynamic model analysis, has allowed us to disclose the phase behaviour of amino-functionalized MIL-53(Al). Similarly to the regular MIL-53(Al) material, the so-called breathing phenomenon was shown to take place in the amino-MIL-53, between a large pore (Ip) and a narrow-pore (np) structure. There are some experimental indications that the transitions are more sluggish in the amino-MIL system. Phase mixtures are also observed.

The temperature-loading phase diagram was derived and compared with the diagram for regular MIL-53(Al). The overall shape of the diagram is similar, and this is explained in terms of the relative affinities of the $\mathbf{n p}$ and the $\mathbf{l p}$ structures for the adsorbate gas. A striking difference is observed in the extent of the np phase stability domain, which is quite larger in the amino-MIL case. This is explained by the increased affinity for $\mathrm{CO}_{2}$ due to the presence of the amino groups in the pore space. Work is in progress to extend this study to gas mixtures.

\section{Acknowledgements}

Ruud Hendrikx at the Department of Materials Science and Engineering of the Delft University of Technology is acknowledged for the X-ray analysis. J.G. gratefully acknowledges the Netherlands National Science Foundation (NWO) for his personal VENI grant. J.F.M.D. acknowledges FWO Vlaanderen for financial support. 


\section{Appendix A. Supplementary data}

Supplementary data associated with this article can be found, in the online version, at doi:xxx 


\section{References:}

[1] A.R. Millward, O.M. Yaghi, J. Am. Chem. Soc. 127 (2005) 17998.

[2] R. Babarao, J.W. Jiang, J. Langmuir, 24 (2008) 6270.

[3] T. Loiseau, C. Serre, C. Huguenard, G. Fink, F. Taulelle, M. Henry, T. Bataille, G. Ferey, Chem. Eur. J. 10 (2004) 1373-1382.

[4] R. Morris, P. Wheatley, Angew. Chem. Int. Ed. 47 (2008) 4966-4981.

[5] J. An, N.L. Rosi, J. Am. Chem. Soc., 132 (2010) 5578.

[6] B. Mu, P.M. Schoenecker, K.S. Walton, J. Phys. Chem. C, 114 (2010) 6464-6471.

[7] S. Keskin, D.S. Sholl, Energy and Environmental Science, 3 (2010) 343-351.

[8] K.L. Mulfort, O.K. Farha, C.D. Malliakas, M.G. Kanatzidis, J.T. Hupp, Chemistry - A European Journal, 16 (2010) 276-281.

[9] P.S. Barcia, L. Bastin, E.J. Hurtado, J.A.C. Silva, A.E. Rodrigues, B.L. Chen, Separ. Sci. Tech., 43 (2008) 3494.

[10] S. Cavenati, C.A. Grande, A.E. Rodrigues, Ind. Eng. Chem. Res. 47 (2008) 6333.

[11] L. Bastin, P.S. Barcia, E.J. Hurtado, J.A.C. Silva, A.E. Rodrigues, B.L. Chen, J. Phys. Chem. C., 112 (2008) 1575.

[12] S. Keskin, D.S. Sholl, J. Phys. Chem. C 111 (2007), 14055.

[13] V. Finsy, L. Ma, L. Alaerts, D.E. De Vos, G.V. Baron, J.F.M. Denayer, Microp. Mesop. Mater. 120 (2009), 221-227.

[14] U. Mueller, M. Schubert, F. Teich, H. Puetter, K. Schierle-Arndt, J. Pastre, J. Mater. Chem. 16 (2006) 626-636.

[15] J.R. Li, R.J. Kuppler, H.C. Zhou, Chem. Soc. Rev. 38 (2009) 1477-1504.

[16] R. Banerjee, H. Furukawa, D. Britt, C. Knobler, M. OKeeffe, O.M. Yaghi, J. Am. Chem. Soc. 131 (2009) 3875-3877.

[17] H. Hayashi, A.P. Cote, H. Furukawa, M. O’Keeffe, O.M. Yaghi, Nat. Mater. 6 (2007) 501-506.

[18] Y.F. Chen, J.Y. Lee, R. Babarao, J. Li, J.W. Jiang, J. Phys. Chem. C, 114 (2010) 66026609.

[19] Q. Xu, D.H. Liu, Q.Y. Yang, C.L. Zhong, J.G. Mi, Journal of Materials Chemistry, 20 (2010) 706-714.

[20] Krishna, R., van Baten, J.M., Journal of Membrane Science, doi:10.1016/j.memsci.2010.05.032

[21] J. Zhang, R. Singh, P.A. Webley, Micropor. Mesopor. Mater. 111 (2008) 478-487.

[22] M. Tagliabue, D. Farrusseng, S. Valencia, S. Aguado, U. Ravon, C. Rizzo, A. Corma, C. Mirodatos, Chemical Engineering Journal, 155 (2009) 553-566.

[23] A. Torrisi, R. G. Bell, C. Mellot-Draznieks, Cryst. Growth Des. 10.1021/cg100646e

[24] V. Zelenak, M. Badaninicova, D. Halamova, J. Cejka, A. Zukal, N. Murafa, G. Goerigk, Chem. Eng. J. 144 (2008) 336. 
[25] X. Xu, C. Song, J.M. Andresen, B.G. Miller, A.W. Scaroni, Micropor. Mesopor. Mater. $16(2003) 1463$.

[26] H.Y. Huang, R.T. Yang, Ind. Eng. Chem. Res. 43 (2003) 2427.

[27] N. Hiyoshi, K. Yogo, T. Yashima, Micropor. Mesopor. Mater. 84 (2005) 357.

[28] R. Chatti, A.K. Bansiwal, J.A. Thote, V. Kumar, P. Jadhav, S.K. Lokhande, R.B.

Biniwale, N.K. Labhsetwar, S. Rayalu, Micropor. Mesopor. Mat. 121 (2009) 84-89.

[29] Z.Q. Wang, S.M. Cohen, J. Am. Chem. Soc. 129 (2007) 12368.

[30] Y. Belmabkhout, R. Serna-Guerrero, A. Sayari, Ind. Eng. Chem. Res., 49 (2010) 359356.

[31] A. Sayari, Y. Belmabkhout, J. Am. Chem. Soc. 132 (2010) 6312.

[32] Y. Belmabkhout, G. De Weireld, A. Sayari, Langmuir 25 (2009) 13275-13278.

[33] T. Devic, P. Horcajada, C. Serre, F. Salles, G. Maurin, B. Moulin, D. Heurtaux, G. Clet, A. Vimont, J.M. Greneche, B. Le Ouay, F. Moreau, E. Magnier, Y. Filinchuk, J. Marrot, J.C. Lavalley, M. Daturi, G. Ferey, J. Am. Chem. Soc. 132 (2010) 1127.

[34] J. An, S.J. Geib, N.L. Rosi, J. Am. Chem. Soc. 132 (2010) 38.

[35] D. Farrusseng, C. Daniel, C. GaudilleÌre, U. Ravon, Y. Schuurman, C. Mirodatos, D. Dubbeldam, H. Frost, R.Q. Snurr, Langmuir 25 (2009) 7383-7388.

[36] R. Banerjee, H. Furukawa, D. Britt, C. Knobler, M. O’Keeffe, O.M. Yaghi, J. Am. Chem. Soc. 131 (2009) 3875-3877.

[37] W. Morris, C.J. Doonan C.J., Furukawa H., Banerjee R., Yaghi O.M., J. Am. Chem. Soc. 130 (2008) 12626-12627.

[38] M. Savonnet, D. Bazer-Bachi, N. Bats, J. Perez-Pellitero, E. Jeanneau, V. Lecocq, C. Pinel, D. Farrusseng, J. Am. Chem. Soc. 132 (2010) 4518.

[39] O.M. Yaghi, M. O’Keeffe, N.W. Ockwig, H.K. Chae, M. Eddaoudi, J. Kim, Nature 423 (2003) 705.

[40] M.J. Ingleson, J.P. Barrio, J. Guilbaud, Y.Z. Khimyak, M.J. Rosseinsky, Chem comm. (2008) 2680.

[41] M. Eddaoudi, J. Kim, N. Rosi, D. Vodak, J. Wachter, M. O’Keeffe, O.M. Yaghi, Science, 295 (2002) 469.

[42] J.L.C. Rowsell, O.M. Yaghi, J. Am. Chem. Soc. 128 (2006) 1304.

[43] B. Arstad, H. Fjellvag, K.O. Kongshaug, O. Swang, R. Blom, Adsorption 14 (2008) 755.

[44] J. Gascon, U. Aktay, M.D. Hernandez-Alonso, G.P.M. van Klink, F. Kapteijn, J. Catal., 261 (2009) 756.

[45] S. Couck, J.F.M. Denayer, G.V. Baron, T. Remy, J. Gascon, F. Kapteijn, J. Am. Chem. Soc. 131 (2009) 6326-6327.

[46] S. Couck, J.F.M. Denayer, G.V. Baron, T. Remy, J. Gascon, F. Kapteijn, Phys. Chem. Chem. Phys. (2010) DOI: 10.1039/b927115e.

[47] A. Torrisi, C. Mellot-Draznieks, R.G. Bell, J. Chem. Phys. 132 (2010) 044705.

[48] Boutin, A.; Springuel-Huet, M.-A.; Nossov, A.; Gédéon, A.; Loiseau, T.; Volkringer, C.; Férey, G.; Coudert, F.-X.; Fuchs, A.H. Angew. Chem. Int. Ed. (2009) 48, 8314-8317. 
[49] S. Bourrelly, P.L. Llewellyn, C. Serre, F. Millange, T. Loiseau, G. Férey, J. Am. Chem. Soc. 127 (2005) 13519-13521.

[50] S. Couck, T. Rémy, G.V. Baron, J. Gascon, F. Kapteijn, J.F.M. Denayer, Phys. Chem. Chem. Phys. (2010) DOI: 10.1039/b927115e.

[51] C. Serre, F. Millange, C. Thouvenot, M. Nogues, G. Marsolier, D. Louer, G. Ferey, J. Am. Chem. Soc. 124 (2002) 13519-13526.

[52] F. Millange F, N. Guillou, R.I. Walton, J.M. Greneche, I. Margiolaki, G. Ferey, Chem. Commun. 39 (2008) 4732-4734.

[53] C. Volkringer, T. Loiseau, N. Guillou, G. Ferey, E. Elkaim, A. Vimont, Dalton Trans. 12 (2009) 2241-2249.

[54] Y. Liu, J.H. Her, A. Dailly, A.J. Ramirez-Cuesta, D.A. Neumann, C.M. Brown, J. Am. Chem. Soc. 130 (2008) 11813-11818.

[56] Coudert, F.-X.;; Jeffroy, M.; Fuchs, A.H.; Boutin, A. Mellot-Draznieks, C.J. Am. Chem. Soc. 130 (2008) 14294-14302

[57] Coudert, F.-X.; Mellot-Draznieks, C.; Fuchs, A.H.; Boutin, A. J. Am. Chem. Soc. 131 (2009) 3442-3443

[58] Coudert, F.-X.; Mellot-Draznieks, C.; Fuchs, A.H.; Boutin, A. J. Am. Chem. Soc. 131 (2009) 11329-11331

[59] Z. Wang and S. M. Cohen, J. Am. Chem. Soc. 131 (2009) 16675-16677

[60] A. V. Neimark, F.-X. Coudert, A. Boutin, A. H. Fuchs, J. Phys. Chem. Lett. 1 (2010) 445-449.

[61] M.A. Springuel-Huet, A. Nossov, Z. Adem, F. Guenneau, C. Volkringer, T. Loiseau, G. Férey, A. Gédéona, J. Am. Chem. Soc (2010) in press.

[62] A. Boutin, F.-X. Coudert, M.-A. Springuel-Huet, A.V. Neimark, G. Férey, A.H. Fuchs, Submitted for publication 


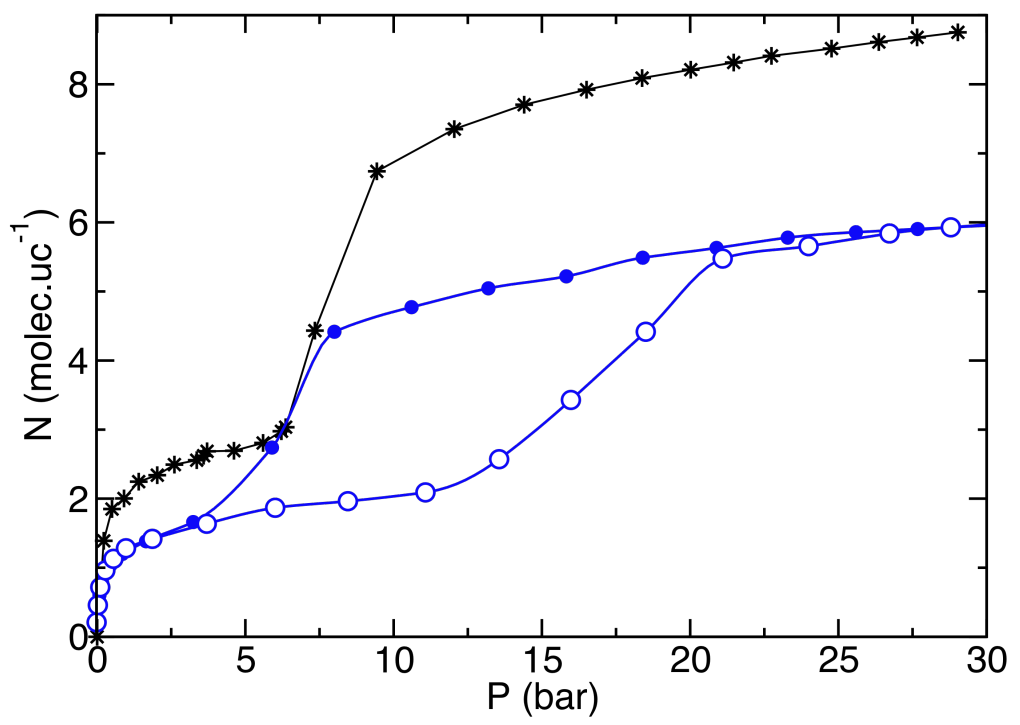

Figure 1: $\mathrm{CO}_{2}$ experimental adsorption-desorption isotherm measured at room temperature $(303 \mathrm{~K})$ in amino-MIL-53(Al) (blue circles). For comparison the adsorption branch of MIL53(Al) (black stars) is included, taken from [49].

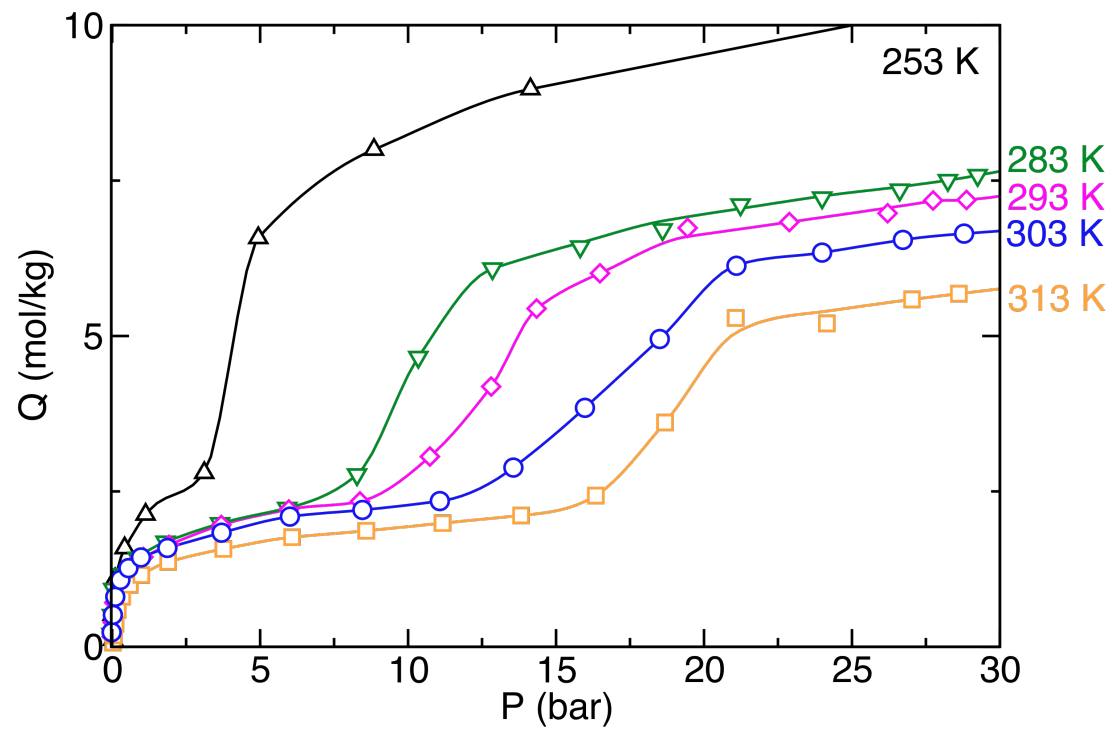

Figure 2: Experimental adsorption isotherms of $\mathrm{CO}_{2}$ in amino-MIL-53(Al) at 253 (black triangles up), 283 (green triangles down), 293 (magenta diamonds), 303 (blue circles) and 313 $\mathrm{K}$ (orange squares). Lines are guide for the eyes. 


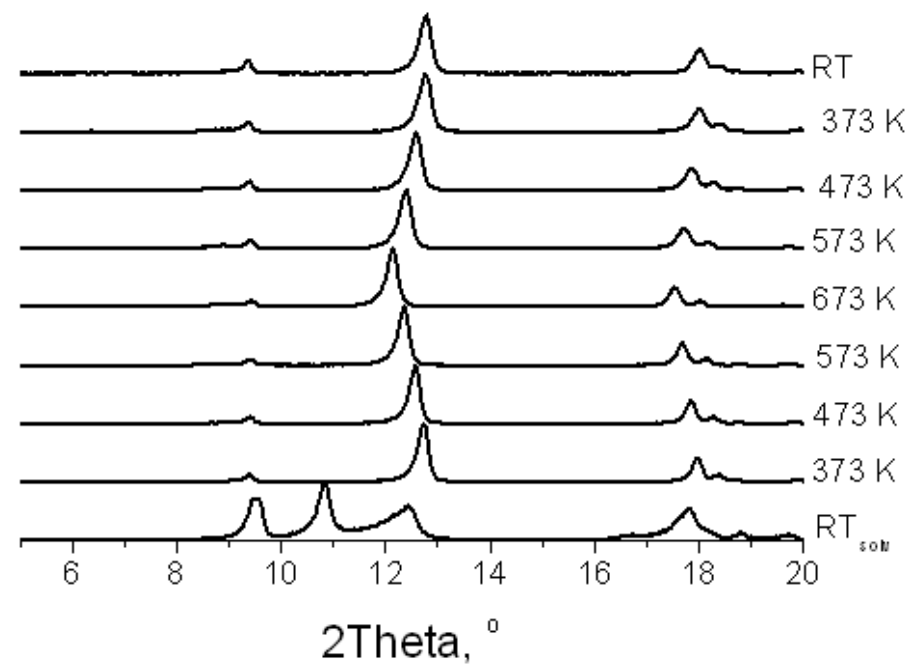

Figure 3: TP-XRD of an $\mathrm{NH}_{2}-\mathrm{MIL}-53(\mathrm{Al})$ sample under $\mathrm{N}_{2}$ atmosphere.

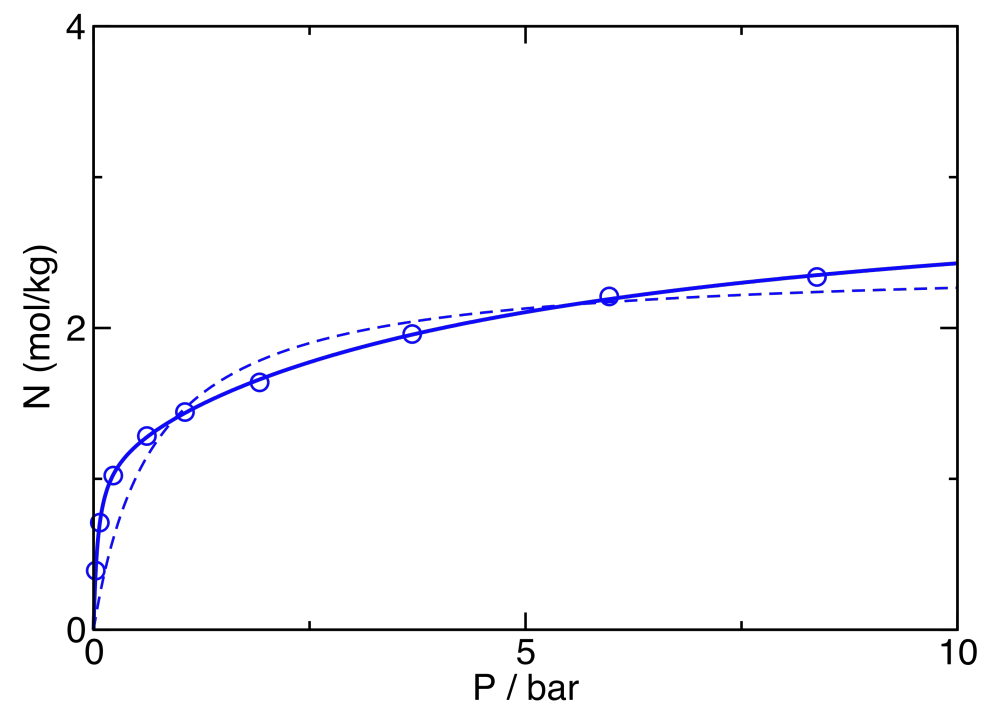

Figure 4: Adsorption isotherm data at $293 \mathrm{~K}$ at low pressures fitted by a single Langmuir equation (dashed line) and a mixture of two Langmuir equations (full line). 


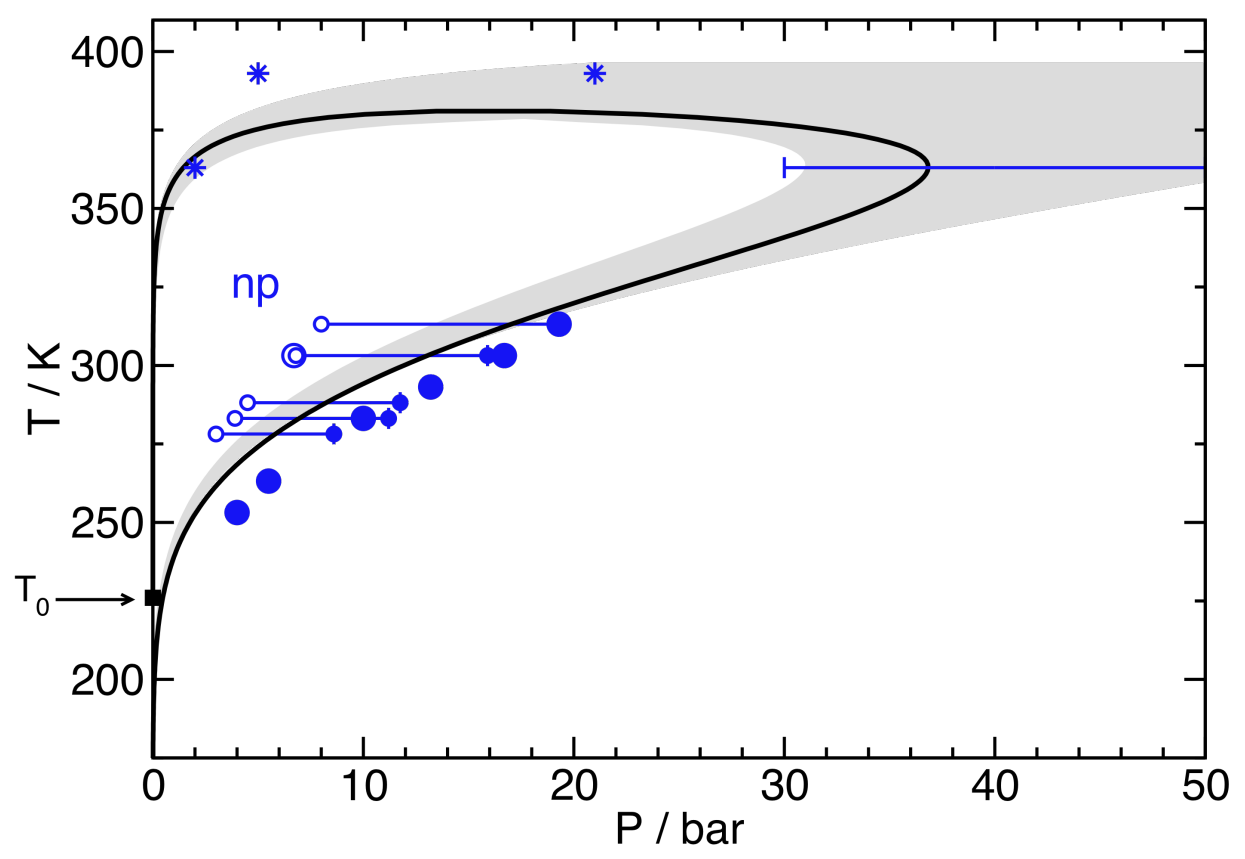

Figure 5: Temperature - $\mathrm{CO}_{2}$ pressure phase diagram of amino-MIL-53(Al). Solid line: osmotic thermodynamic model. Grey zone corresponds to an arbitrary uncertainty of \pm 1 kJ.mol-1 introduced in the osmotic potential. Filled and open symbols are experimental transition steps in the adsorption and desorption isotherms respectively. The two distinct sizes of symbols correspond to two sets of experiments performed on different samples. The stars correspond to estimates of transition pressure for the two highest temperatures experimental adsorption isotherms measurements using the osmotic thermodynamic model. $\mathrm{T}_{0}$ is the equilibrium phase transition temperature between the $\mathbf{l p}$ and $\mathbf{n p}$ phases at zero pressure (i.e. the empty material). 


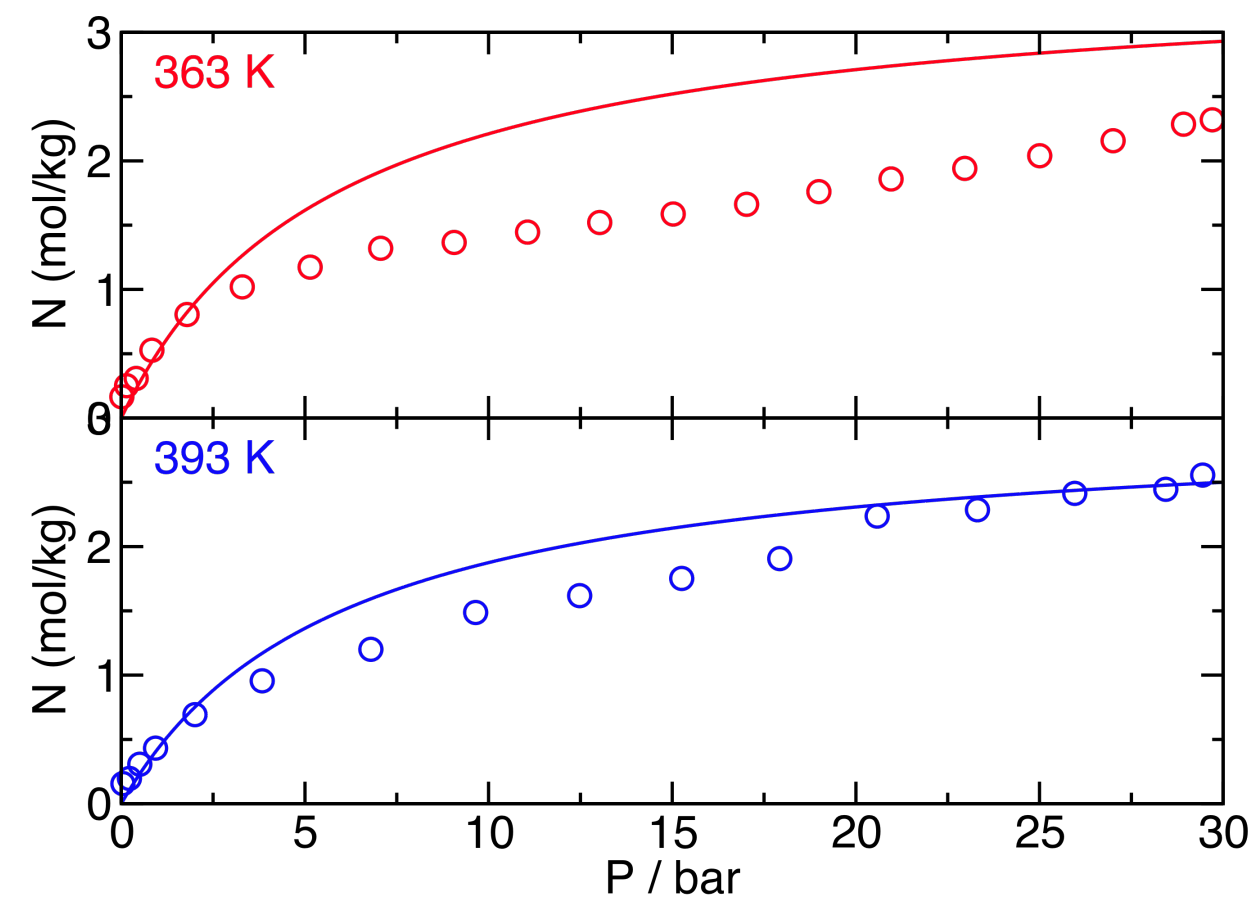

Figure 6: Experimental adsorption isotherms at 363 and $393 \mathrm{~K}$. Lines correspond to the Langmuir model isotherms in the lp phase extracted from the fitting of the lower temperature isotherms.

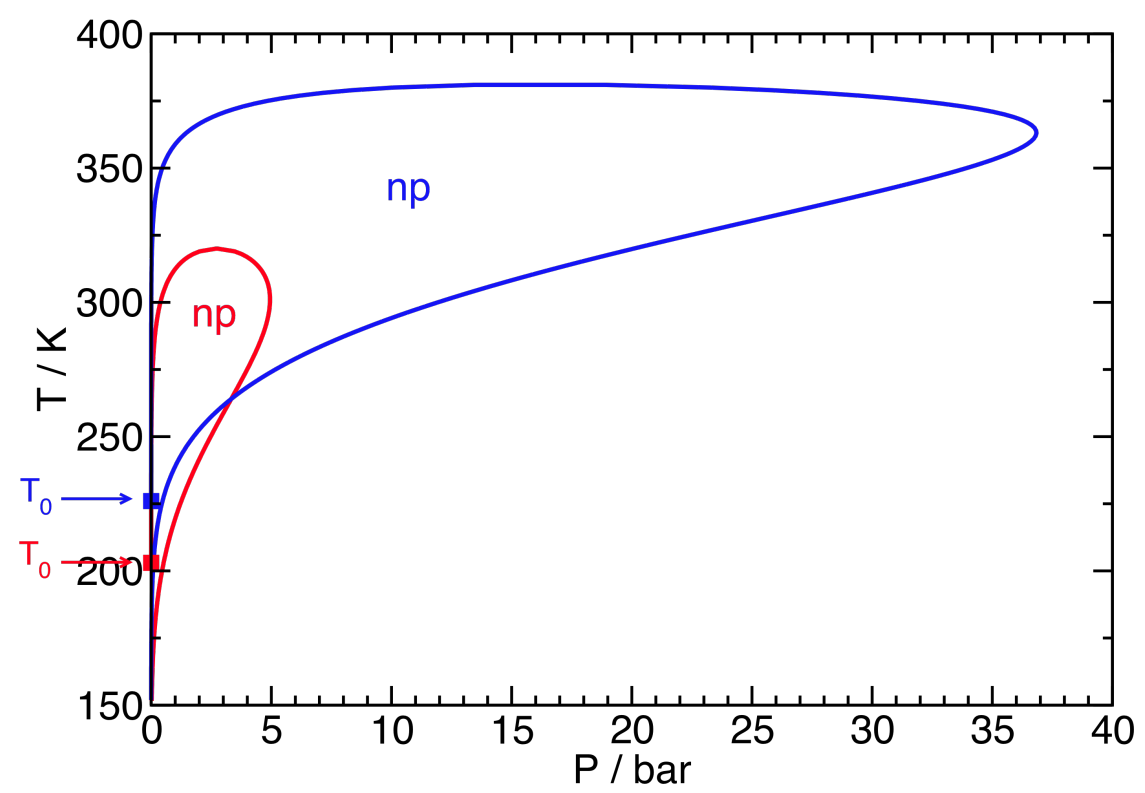

Figure 7: Temperature - $\mathrm{CO}_{2}$ pressure phase diagrams for regular (red) and aminoMIL53 (blue) materials. $T_{0}$ are the equilibrium phase transition temperature between the lp and $\mathbf{n p}$ phases at zero pressure (i.e. the empty material) for both materials. 